\title{
Preclinical Patient Case Scenario as an Aid to Clinic Preparation: "A Day in the Clinic"
}

\author{
Gary L Drahos* \\ College of Dental Medicine, Midwestern University, Downers Grove, Illinois, USA \\ *Corresponding author: Gary L Drahos, College of Dental Medicine, Midwestern University, Downers Grove, \\ Illinois, USA, Tel: +1 6305157473; E-mail: gdraho@midwestern.edu
}

Received Date: 27 June 2017; Accepted Date: 31 August 2017; Published Date: 27 October 2017

\section{Abstract}

Introduction: Pre-clinical dental curriculum, even when taught in an integrated manner, often does not prepare the student to provide competent, ethical patient care of the highest quality or aid with their transition to the patient care clinic. Student competencies are usually assessed in only one specific area and not contextualized in a patient care scenario. Exposing preclinical students to a high fidelity simulated patient care scenario will help the student develop critical thinking and dental treatment skills that will prepare them to plan for actual patient treatment in the clinic.

Methods: A patient scenario was developed that integrated multiple disciplines and contextualized common clinical situations that are encountered daily when treating patients in the clinic including interviewing skills, basic diagnostic skills, manipulation of electronic patient records, material selection and defense of selection, oral pathology diagnosis, image and data procurement, critical decision making, treatment planning and performance of dental treatment. This scenario was designed for second year dental students to be completed in a $3 \frac{1}{2}$ hour session. The students were required to make critical patient care decisions and self-assess their performance. Faculty assessed student preparedness for the clinic by applying criteria sheets that were developed for each case.

Results: Students generally completed the session on time and in a satisfactory fashion. Preparation for the session was key and faculty calibration was essential.

Conclusion: Completion of this case scenario better prepared the students for the clinic as indicated by student self-assessment, post course satisfaction surveys, narrative comments, and faculty assessments.

\section{Keywords}

Clinic Preparation; Critical Thinking; Dental Materials; Electronic Health Record; Oral Pathology

\section{Educational Objectives}

After completing this simulated patient session, learners will be able to:

- Demonstrate critical thinking when selecting patient treatment materials.

- Demonstrate professionalism and time management when working on dental manikins in a team dental setting.

- Demonstrate competency in differential oral pathology diagnosis and treatment.

- Demonstrate appropriate patient interview skills.

- Demonstrate image procurement skills and manipulation of data in the electronic health record.

- Demonstrate the ability to self-assess their dental treatment while working independently.

- Demonstrate performance of basic dental skills.

\section{Introduction}

Preclinical curriculum is designed to teach basic foundational knowledge. A dental education must build on basic understanding of dentistry (with additional knowledge in the biomedical sciences) that the student can apply to simulated clinical scenarios and ultimately clinical cases. The first two years in a typical dental curriculum are devoted to ensuring that the students acquire this foundational knowledge prior to dental treatment of patients. The challenge has always been to create a clinic atmosphere in the preclinical environment. Most assessments of preclinical patient skills are in the form of Independent Clinical Performance Assessments (ICPA) that test only one focused aspect of the clinical experience (specific restorative preparations, restorations, endodontic procedures etc.). Some sessions involving simulated 
Citation: Drahos GL (2017) Preclinical Patient Case Scenario as an Aid to Clinic Preparation: “A Day in the Clinic”. J Dent Sci Res Ther 2017 : 1-16. DOI : https://doi.org/10.29199/2637-7055/DSRT.101012.

patients have been developed using the case scenario basis, but most have been for testing purposes [1,2] or for defined areas of dental practice such as oral surgery [3], or the geriatric [4], or removable partial dentures [5]. Search of literature reveals no case scenarios have been developed that have electronic health record, manikin performance, and simulated patient components. Simulated patient scenarios using an electronic health record, posted patient narrative and faculty acting as simulated patients, contextualizes learning concepts in preparation for patient care. The simulated patient also provides a realistic insight into actual routine clinic situations requiring multiple levels of critical thinking, decision making, organization and time management skills. A pre-clinic session, that has the same time allotment as clinic treatment sessions ( 3.5 hours), is designed to mimic uncomplicated patient treatment scenarios that present routinely in the clinic.

This simulated patient scenario was developed to allow faculty to assess student skills, provide for student self-assessment and demonstrate individual performance. In this scenario second year dental students were scheduled to work in pairs on the assigned patient and perform dental procedures. This case scenario required demonstrations and performance of indirect restorations, direct restoration tooth preparation, impression procedures, 4 handed dentistry, occlusion, esthetic restorations, radiograph procurement and interpretation, and a detailed daily treatment note using a template. The students were required to demonstrate competency in the following: patient interview, demonstration of blood pressure procurement, diagnosing common oral pathology (Geographic Tongue), patient data collection and recording in the EHR, evaluation of oral health, and restoration material selection. Faculty act as the patient and answer any student's questions concerning existing conditions, current health and determination of restoration material selection. Student's professional and clinical skills were assessed by the following methods: student self-assessment using criteria sheets that have been established throughout the first two years, independent performance and faculty observation. Faculty calibration was important for success of this session. Following completion of the "Day in the Clinic" session the students should be better prepared to provide competent, ethical patient care of the highest quality and aid with their transition to the patient care clinic.

\section{Methods}

The rationale for including a preclinical patient scenario in the curriculum, is to allow the student to apply basic dental knowledge and perform basic dental procedures in the context of a simulated patient. The essence of the "A Day in the Clinic" session is creating a plausible, uncomplicated simulated patient that requires routine dental treatment and has common health conditions. This scenario requires multiple areas of decision making that allow the student to demonstrate critical thinking, diagnostic abilities and skill in providing dental treatment. The complexity of this case is commensurate with the timing of the basic knowledge that the student has accumulated at that point in the curriculum. This simulated patient was created by representative faculty from the various teaching disciplines and specialties. This patient scenario consisted of three parts.

\section{The Electronic Health Record (EHR)}

The first component (Appendix A) is the patient's Electronic Health Record (EHR) which contains the treatment plan and the treatment to be accomplished on the day of the session as well as the patients' health history, dental history and previous dental visits. Key components for the patient treatment are contained in the EHR (such as medications, preference for restoration material, radiographs and photos, health and dental histories). This electronic health record John Doe was created and duplicated to each student's active patient roster in the electronic health record at the beginning of the course.

\section{The narrative part}

The case scenario narrative component (Appendix B) gives information about the patient as he presents for today's appointment. The student must factor in this information when considering today's treatment (blood pressure, oral pathology and special instructions for the students). The narrative aspect of this case was posted to the all students on an electronic website at the beginning of the course.

\section{The faculty}

The supervising faculty serve in the dual role as observing faculty (for assessment purposes) and the patient (for the student to ask questions and obtain information that might affect the day's treatment such as new medications, oral conditions, restorative material preferences etc.) (Appendix C). The session is implemented in the summer quarter for the second year dental students. They had at this time completed 6 quarters of preclinical curriculum. The class of 128 students was divided into 16 groups of eight students. One faculty member facilitated each group for a total requirement of 16 faculty.

This interaction of patient/faculty and student is an important phase of the session and allows for a thorough determination of the students preparedness and knowledge of the patient, procedures to be performed and patients health in relation to performing the planned treatment.

\section{During the session}

The students should be graded using the grade sheet (Appendix D):

Each student has this patient reproduced to their individual patient base in the EHR and they must both enter the information individually in their patients record. The session concludes with the daily treatment note following a six-part template created for the exercise (Appendix E).

\section{Format}

The scenario requires the students to work as a paired team, with one performing dental treatment, and the other assisting (students previously have been instructed in 4 handed dentistry utilization). Two students in the DMD2 class were paired randomly (Student A and B). The patient is treatment planned to have 2 procedures 
completed on the day of the session (a restorative procedure and a crown procedure). The restorative procedure is to be performed by student A with student $\mathrm{B}$ acting as the dental assistant, and the crown procedure was to be performed by student $B$ with student $A$ acting as the dental assistant. The choice of which dental student did which procedures was up to the paired student team. All dental treatment procedures are to be performed on a typodont that is positioned in a dental manikin.

\section{Session Components}

\section{Patient presentation to the instructor}

The students will provide a concise and organized presentation of case facts to the supervising instructor prior to proceeding with patient treatment. Key factors that were provided in the narrative summary were a change in measured Blood Pressure (BP), a requirement to procure and attach a radiograph of $\# 18$, a requirement to demonstrate the proper procurement of the patients BP(on each other), and the patient reporting a recurring oral lesion that he describes and requests a diagnosis and treatment options.

\section{$18 \mathrm{MO}$ restoration}

The previous EHR treatment note calls for an MO restoration to be placed in tooth \#18 (radiograph provided), but the restorative material is not specified. The EHR is vague in that the patient states, in the dental history section "I want my teeth fixed. I want the strongest fillings you can place. Please make them esthetics, but metal fillings are OK also". The students paired to this case will have to decide what preparation and restoration to place (amalgam or composite). It is anticipated that the students will need to interview the "patient" (instructor) to present the characteristics of the two materials and determine what the patient wants to be placed. Patient decisions need to be made with consideration for the merits of both materials as well as esthetics, longevity, abilities of the student and cost. It is expected that prior evidence based research on this topic will be performed by the students so that an organized presentation to the patient (faculty) is made on the date of the session with factual basis (student opinion that one restorative material is stronger than another needs to be based on research results). The patient (faculty) will decide what material will be used and Student A of the pair of students will proceed with the preparation and placement of the restoration while student B assists.

\section{\#30 Metal crown preparation and impression and provisional}

The second procedure to be performed is a crown preparation, for an all metal crown, that has been treatment planned for a tooth that has fractured cusps. Student B will perform this procedure and is also expected to procure a triple tray impression of the prepared tooth and make a provisional restoration. The narrative instructions inform the students to make only one attempt at procuring an impression and making a provisional. If the student assessed the results to be unsatisfactory, they are required to explain why the results were unsatisfactory and what corrections need to be made in order to obtain satisfactory results. Student A will assist. The students are allowed to ask the patient (instructor) and questions or interview them in a fashion to obtain information that they think is critical to the dental treatment.

\section{Blood pressure procurement}

The students will demonstrate to the instructor, as a team, how to procure a blood pressure measurement with a cuff and stethoscope.

\section{Radiograph procurement and attachment to the EHR}

The students are also instructed in the narrative to procure and attach to the EHR a digital radiograph of tooth \#30 procured in the adjacent radiology facility using standardized radiology manikins and typodonts.

\section{Oral Lesion diagnosis and treatment}

Additionally, in the narrative section, the patient complains of a recurrent issue with his tongue that will require diagnosis. The appearance of the lesions is available in a photograph attached to the EHR. The student is expected to interview the patient (faculty) when formulating a diagnosis. The history of this lesion and analysis of the photo will result in a diagnosis of benign migratory glossitis (geographic tongue) requiring no treatment.

\section{Session Treatment Note in the EHR}

The students use a template to create an organized session note (Appendix F).

\section{Assessments}

The students were assessed by the faculty using case scenario specific assessment checklists. A unique checklist was developed for student A and student B (Appendix E).

\section{Calibration sessions}

Students: were calibrated to the exercise in a lecture format using a PowerPoint presentation. The electronic health record entry for the patient was also demonstrated.

Faculty: calibration to ensure uniformity in student assessment was presented in the lecture format using a PowerPoint, faculty guide and the demonstration of the electronic health record information.

Resources required to present this session, include access to electronic website to post sessional material such as patient narrative scenarios, calibration presentations, assignments and criteria sheets. An accessible electronic health record system (preferably the same one as used by students in the clinic) also is required. The session requirements for dental materials, instruments are contained in (Appendix G). Facilities, faculty and electronic hardware are all items available in a typical dental pre-clinical environment.

\section{Results}

One Hundred Twenty-Eight (128) DMD-2 students participated in this session during the summer academic quarter of 2016. 
Using case specific assessment criteria, student self-assessment criteria and observations, faculty graded the students to have satisfactorily completed $81 \%$ of all cases scenario challenges. There were 3 instances where one of the paired students performed satisfactorily and the other was graded unsatisfactory. 55\% of the students ultimately chose (and convinced the patient to choose) amalgam as the permanent MO restoration for \#18MO. Each successful completion of a case resulted in $1 \%$ of their course grade. All students then completed the final exam multiple choice assessment (80 questions) which contained 8 questions related to this session. Outcomes, for this written assessment, were not examined to determine the level of student performance specifically on "A Day in the Clinic" questions. 122 (95\% of the class) participants responded to a post session online evaluation with an overall rating of 4.63 out of 5 in the areas of clarity of objectives, organization, evaluation methods and overall rating. Narrative comments (55) were also positive. Two areas that the students seem to have some difficulty with are: 1 . The patient interview process to obtain information necessary to diagnose the urgent care problem (faculty portrays the patient) 2. Defending the selection of appropriate restorative material.

\section{Discussion}

The concept of "A day in the Clinic" was generated to simulate clinical situations that would occur on a typical clinical patient. Developing a realistic patient scenario that contained components contained in numerous areas of the preclinical curriculum was a positive experience for the students, and gave a palpable feeling of how patient treatment will be performed in the dental clinic. Contextualizing various basic dental knowledge components into this case forced the students to prepare ahead, verbalize a presentation of case facts to the faculty and also organize their plan of action to perform the planned treatment. Performing daily data gathering such as updating medical and dental histories with new information, manipulating the EHR to add radiographs and treatment notes, and defending dental material choices were all pieces of this session. Faculty responses, when role playing the patient, also added an interview aspect to the session. The results of the post course evaluation indicated students found value in this type of session and helped anticipate the real nature of patient treatment in the clinic. The authors are unaware of other courses commonly used in dental school education today that offer a similar level of pre-clinical training experiences in simulation of daily common case scenarios as provided by this session. The material and facilities needed to accomplish these sessions are typical items that are found in every preclinical simulation lab.

The "A Day in the Clinic" concept is not without its problems. Developing an appropriate case scenario is always a challenge.
The final goal of completing the treatment in the time allowed and not trying to include too many items into the scenario is important. This simulated patient scenario approach to teaching requires much faculty and student calibration to insure accurate and fair assessing of the student. Criteria forms that are developed for this type of assessment are essential and allow for fair individual assessment.

\section{Suggestions for Expanding the Role of "A Day in the Clinic" Sessions}

This patient scenario session can be adapted as the students' progress through the preclinical curriculum and treatment modalities can be added as their knowledge base increased. For instance, patient consults, fixed prosthetics, complex oral lesions, prescription writing and more can be added to the elements of the scenario as the students develop these skills. Case difficulty and inclusion of more critical thinking decisions and complexity of the dental treatment can increase toward the end of the second year. Patient case scenarios can be tailored to any phase of the curriculum.

\section{Conclusion}

The students seemed to genuinely enjoy the multiple procedures that they had to perform during this session as evidenced by their written narrative evaluation and verbal comments concerning this session. Simulating a real clinic case and providing all the treatment necessary for that day required organization, planning and preparation. Working in a 4 handed environment was also a new experience for them. This session gave them a first-hand view of how the clinical treatment of patients would occur and prepared them for treating patents in the clinic. It also helped identify areas of patient care that need to be revisited in preclinical curriculum.

\section{References}

1. Pulido M, Morrow J, Smith B, Murad A, Halket C, et al. (2014) Assessing Procedural Skills, Manual Dexterity, and Operator Efficiency in a Comprehensive Preclinical Examination. MedEdPORTAL Publications 1: 9754.

2. Morrow J, Pulido T, Smith B, Murad A, Halket C, et al. (2014) A New Paradigm in Simulation Clinic Practical Examinations: A Design to Stimulate Critical Thinking. MedEdPORTAL Publications 10: 9810.

3. Weiner $C K$, Skålén $M$, Harju-Jeanty $D$, Heymann R, Rosén $A$, et al. (2016) Implementation of a Web-Based Patient Simulation Program to Teach Dental Students in Oral Surgery. J Dent Educ 80: 133-140.

4. Johnson LA, Cunningham MA, Finkelstein MW, Hand JS (1997) Geriatric patient simulations for dental hygiene. J Dent Educ 61: 667-677.

5. Echeto L(2016)Removable Partial Denture Components andApplications: ATeam-Based Learning Module. MedEdPORTAL Publications 12: 10408.

\title{
Appendix A: Patient electronic health record requirements
}

\author{
Electronic Health Record requirements (EHR)
}

1. Create a patient in the EHR (John Doe).

2. Use demographics (Age 63, DOB 7/4/53, address, phone and other demographics appropriate for your area.

3. Create an odontogram indicating the all teeth are present except \#1 and 32 and indicate that \#18 has an MO caries (radiograph \#1) 
and \#30 has fractured mesial, facial and occlusal structure (sufficient to require a full crown coverage. The odontogram would look like the image below:

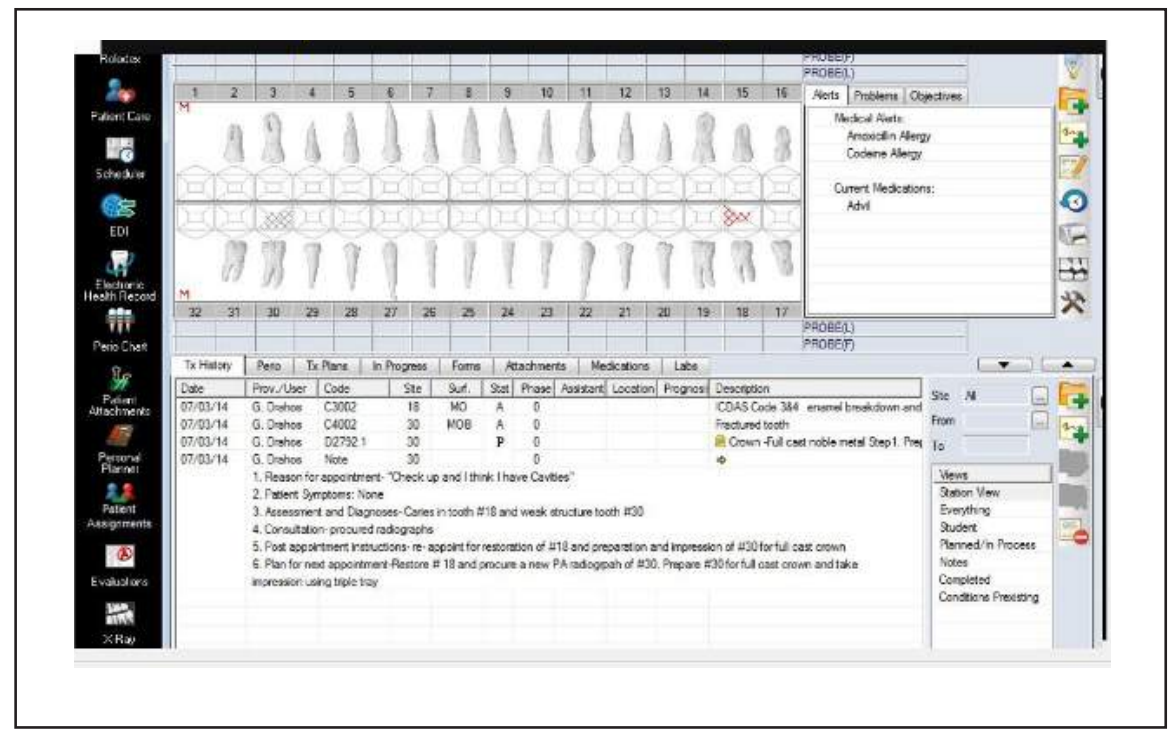

4. The EHR should also have appropriate entries to indicate that the patient has been seen previously for and exam and that the health history, dental history and medications as well as the above condition. The health history would be normal except for allergies to amoxicillin and codeine, and the patient takes Advil as needed for arthritis- 2 OTC tablets daily. His health is normal, he has a doctor of record that he has seen in the last year, his BP is 135/90, he has never been hospitalized and his reason for coming is "I want my teeth fixed. I want the strongest fillings you can place. Please make them esthetics, but metal fillings are OK also".

5. He sees that dentist every couple of years and was last seen 2 years ago. He complains of a funny looking tongue that occurs every now and then, but is not sore or painful and just "kinda goes away". He has it now and a photo was taken at his first appoint and is attached to the EHR (Photo 1). The rest of the oral exam reveals normal conditions.

6. At the patients first appointment he was treatment planned for an $18 \mathrm{MO}$ restoration and a metal crown on \#30. The \#18 MO preparation and restoration and impression of $\# 30$ and provisionalization are to be accomplished at the next appointment (today).

Radiograph \#1

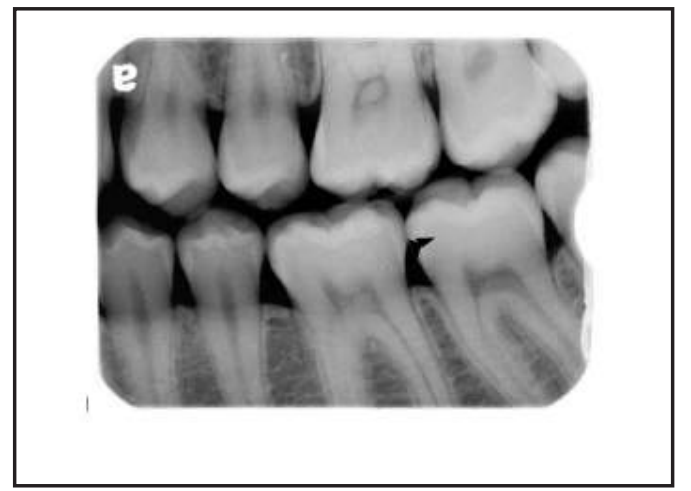

Photo \#1

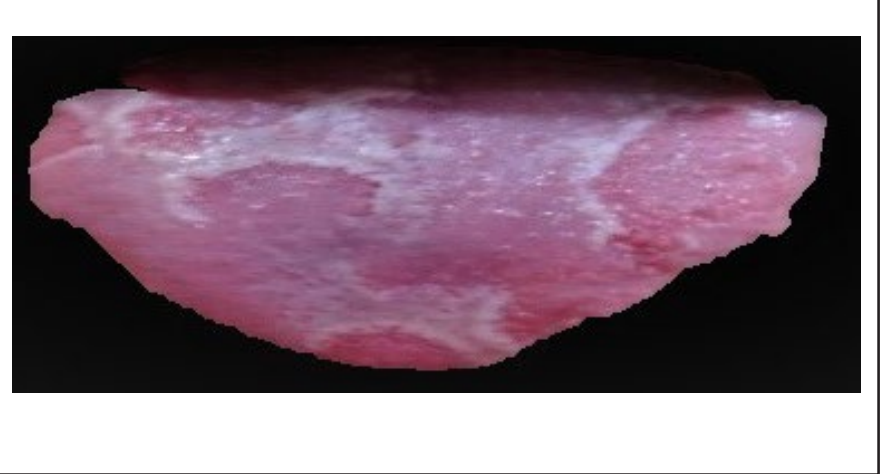




\section{Appendix B: Case narrative (posted 1 week prior to the session)}

\section{A day in the clinic}

Your patient for this session is John Doe. His patient record is available to you in the EHR. The previous treatment note will let you know what is planned for the patient for today. His blood pressure today is $140 / 85$. Another student in your group is assigned with you for this treatment session. There is a 4-handed dentistry component to this session. After reviewing the patient's chart, you should update the patient's medical history. The patient has also noticed some irregularities in his tongue that he says reoccurs occasionally. Please advise him as to the most likely diagnosis and treatment necessary.

1. Present the facts of the case to your instructor

- Why the patient is here today

- Health history (including any new findings)

- Plan for today's session

2. Once the instructor has approved your plan, proceed with the exercise.

3. Have the assigned faculty check intermediate steps.

4. Use the appropriate criteria forms as a guide and include a self-assessment.

5. The final assessment for this session will be satisfactory/ unsatisfactory. The exercise will be graded as a whole (for both students) and include assessments of all the phases leading to and including treatment (just like in the clinic).

6. The faculty supervisor will act as the patient if you need to question or obtain information from the patient.

\section{Tips:}

1. Before the session, assemble all materials, instruments, and criteria forms necessary to provide treatment for this exercise. Review all necessary procedures, previous course documents and literature to aid in providing patient care today.

2. Familiarize yourself with the details of this scenario and the facts as posted in the patient HER.

3. Decide how the dental procedures will be divided between yourselves.

4. Assemble the appropriate equipment and demonstrate to your instructor the exact method you would use to procure the patients BP.

5. Write a description of what you see on the patients tongue in the extra/intra oral section.

6. Take only one impression and make only one provisional- if it is not acceptable, be prepared to explain this to the supervising faculty member

\section{Appendix C: Faculty guide for the session}

Faculty guide to "A Day in the Clinic"- Patient John Doe

Prior to the "Day in the Clinic Session"

1. Electronic Health Record Preparation: A patient (John Doe) is created in the students Electronic Health Record (EHR) with the health history, dental history, attached radiograph, photos and a treatment plan for the session (Appendix A)

2. A narrative description for patient John Doe: This is data for the patient pertinent to the date of the session needs to be created and posted at the beginning of the course (Appendix B)

3. Student preparation for the session: Students should decide prior to the session what their responsibilities will be in the role of Student A and B and plan their faculty presentation, organizational roles and responsibilities in the dental team.

\section{Tips for student preparation prior to the session:}

- Before the session, assemble all materials, instruments, and criteria forms necessary to provide treatment for this exercise. Review all necessary procedures, previous course documents and literature to aid in providing patient care today. 
- Familiarize yourself with the details of this scenario and the facts as posted in the patient EHR.

- $\quad$ Decide how the dental procedures will be divided between yourselves.

- Assemble the appropriate equipment and demonstrate to your instructor the exact method you would use to procure the patients BP. Students must make restorative material selection as a result of patient (faculty) consultation.

*Have evidence ready to support your claims (is amalgam "stronger" than composite etc.). Be sure of your facts. Amalgam, composite, glass ionomer, temporary.

*Consider the area you are restoring.

*Final restoration or bases.

*Don't make decisions without consulting the patient (they may think that metal fillings are more esthetic than white fillings).

On the day of "Day in the Clinic" Session (12 - 3:30 PM - or any other 3.5 hour period) Student A and B Presentation to the assigned faculty

1. Present the facts of the case

- Why the patient is here today

- Discuss the health history (including any new findings- entered into appropriate module of EHR)

- $\quad$ Plan of treatment for today (from notes in EHR)

2. The student can proceed once you have approved of the presented treatment

3. Before the session, assemble all materials, instruments, and criteria forms necessary to provide treatment for this exercise. Review all necessary procedures, previous course documents and literature to aid in providing patient care today.

4. The student must be very familiar with the facts of this case and able to answer any questions you, the instructor, may have

5. Students decide how the dental procedures will be divided between yourselves.

6. Students assemble the appropriate equipment and demonstrate to your instructor the exact method you would use to procure the patients BP

7. The student should have the dental manikin prepared with the correct typodont configuration (as charted in the EHR) in the mouth (Appendix C)

8. The work area should be organized with appropriate cassettes and material laid out in an orderly manner.

9. The faculty maintains a dual role:

- As a faculty member to quiz the student on any part of the presentation as well as the patients health history and any other issues the student may present,

- As the patient. -The student may ask any questions of the patient (faculty) that may be necessary and the patient may ask any questions of the student concerning the procedures to be performed this day. 


\section{Appendix D: Self Assessment Criteria Sheets for various procedures performed during the session}

\begin{tabular}{|c|c|c|c|}
\hline \multirow{2}{*}{\multicolumn{4}{|c|}{$n-T o$}} \\
\hline & & & \\
\hline \multicolumn{2}{|c|}{ Student name: } & \multicolumn{2}{|l|}{ ate: } \\
\hline Criteria & Meets Expectations & Does Not Meet Expectations & Comments \\
\hline \multicolumn{4}{|l|}{ Margins } \\
\hline & $\begin{array}{l}\text { Prep margin is located no more than } 1.0 \mathrm{~mm} \text { above the } \\
\text { gingival margin and/or no more than } 0.5 \mathrm{~mm} \text { below the } \\
\text { gingival margin. }\end{array}$ & $\begin{array}{l}\text { Prep margin located greater than } \\
1.0 \mathrm{~mm} \text { above the gingival margin } \\
\text { and/or greater than } 0.5 \mathrm{~mm} \text { below } \\
\text { the gingival margin. }\end{array}$ & \\
\hline & $\begin{array}{c}\text { Prep margin is smooth to slightly rough, and is defined } \\
\text { or has slight loss of definition. }\end{array}$ & $\begin{array}{l}\text { Prep margin has little definition } \\
\text { and is extremely rough. "J" margin } \\
\text { present with unsupported enamel. }\end{array}$ & \\
\hline & $\begin{array}{l}\text { Prep margin is continuous } 360^{\circ} \text { around tooth or has minor } \\
\text { areas of discontinuity. }\end{array}$ & $\begin{array}{l}\text { Prep margin has little continuity } \\
360^{\circ} \text { around tooth. }\end{array}$ & \\
\hline & $\begin{array}{l}\text { Prep margin design is chamfer. Margin width no greater } \\
\text { than } 1.5 \mathrm{~mm} \text { at any point on circumference. }\end{array}$ & $\begin{array}{l}\text { Prep margin design anything oth- } \\
\text { er than chamfer. Margin width is } \\
\text { greater than } 1.5 \mathrm{~mm} \text { at any location } \\
\text { on circumference. }\end{array}$ & \\
\hline \multicolumn{4}{|l|}{ Prep Walls } \\
\hline & Prep walls are smooth to slightly rough. & Prep walls are extremely rough. & \\
\hline & No undercuts present on any axial wall of prep. & $\begin{array}{c}\text { Undercut present on any axial wall } \\
\text { of prep. }\end{array}$ & \\
\hline & Walls have taper ranging from $6^{0}$ to $24^{0}$. & Walls taper greater than $24^{0}$. & \\
\hline & $\begin{array}{l}\text { Prep line angles and cusp tips rounded or demonstrate } \\
\text { slight sharpness of line angles/cusps tips. }\end{array}$ & $\begin{array}{c}\text { Prep line angles or cusp tips very } \\
\text { sharp with no evidence of round- } \\
\text { ing. }\end{array}$ & \\
\hline
\end{tabular}

\section{All Metal Crown Preparation - Tooth \#30}

Student name:

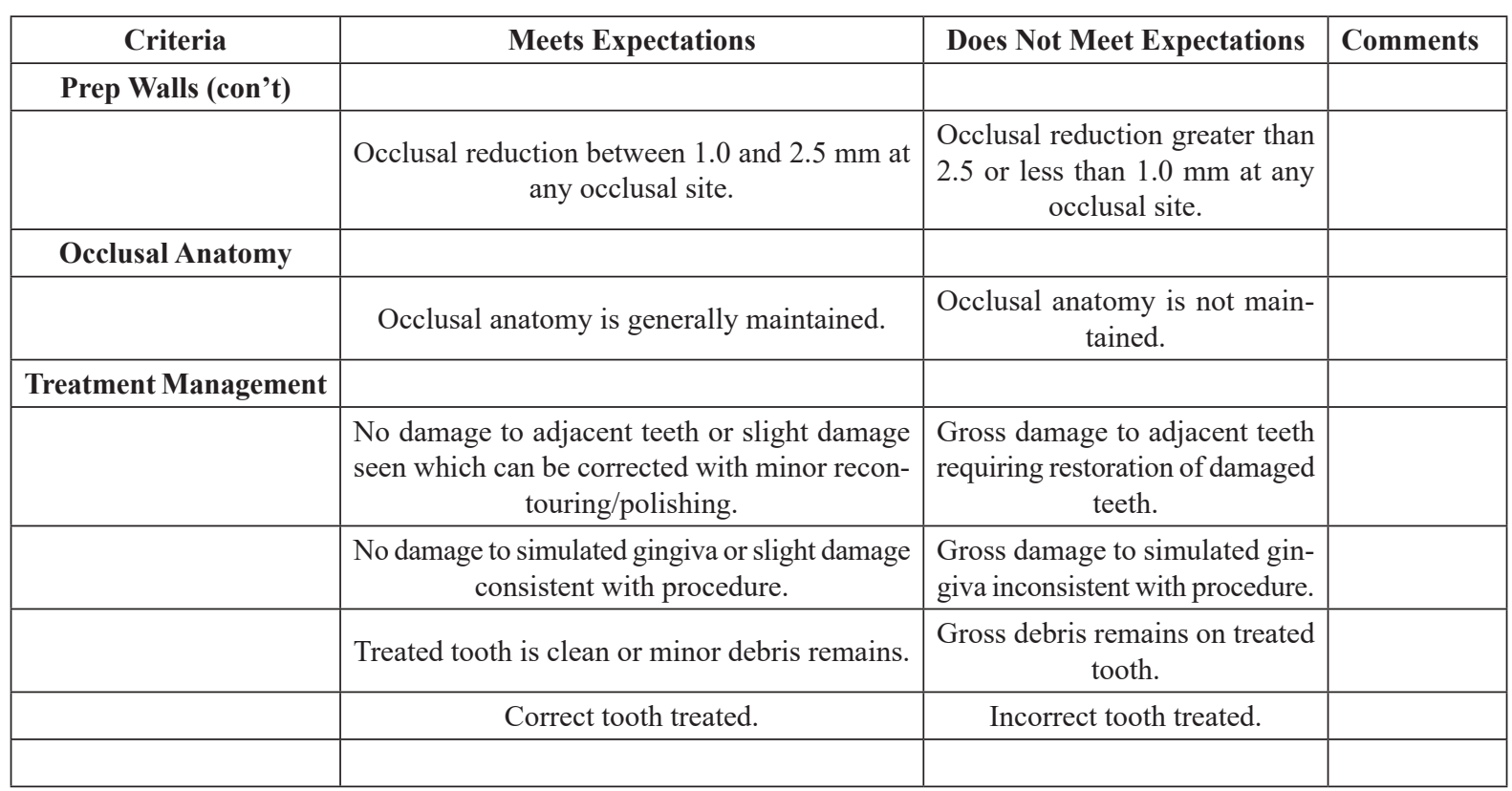


Evaluation of Dental Assistant for Foundation Restoration Activity

\begin{tabular}{|c|c|c|c|}
\hline Criterion & Meets Expectations & $\begin{array}{l}\text { Does Not Meet Ex- } \\
\text { pectations }\end{array}$ & Comments \\
\hline $\begin{array}{l}\text { Assistant positioned } \\
\text { properly }\end{array}$ & $\begin{array}{l}\text { 1. 2- } 4 \text { o'clock for } \\
\text { RH (8-10 LH) }\end{array}$ & $\begin{array}{l}\text { 1. Inappropriate po- } \\
\text { sition of the dental } \\
\text { assistant }\end{array}$ & \\
\hline $\begin{array}{l}\text { Assistant prepared } \\
\text { the necessary in- } \\
\text { struments for the } \\
\text { procedure }\end{array}$ & $\begin{array}{l}\text { 1. All the proper } \\
\text { instrument for the } \\
\text { procedure are se- } \\
\text { lected } \\
\text { 2. Instrument are } \\
\text { arranged in order } \\
\text { of use }\end{array}$ & $\begin{array}{l}\text { 1. All the instru- } \\
\text { ments for the pro- } \\
\text { cedure not ready for } \\
\text { use resulting in the } \\
\text { need to search for } \\
\text { needed instruments }\end{array}$ & \\
\hline $\begin{array}{l}\text { Assistant transfers } \\
\text { the instrument/ma- } \\
\text { terial in an appro- } \\
\text { priate manner }\end{array}$ & $\begin{array}{l}\text { 1. Smooth transfer } \\
\text { of instruments and } \\
\text { materials with no } \\
\text { wasted motion }\end{array}$ & $\begin{array}{l}\text { 1. Improper instru- } \\
\text { ment transfer re- } \\
\text { sulting in dropped } \\
\text { instruments or ma- } \\
\text { terials }\end{array}$ & \\
\hline Patient safety & $\begin{array}{l}\text { 1. No instruments } \\
\text { passed over the pa- } \\
\text { tients face } \\
\text { 2. Instruments not } \\
\text { dropped when trans- } \\
\text { ferred }\end{array}$ & $\begin{array}{l}\text { 1. Instrument trans- } \\
\text { ferred in a hazard- } \\
\text { ous way jeopardiz- } \\
\text { ing the patient } \\
\text { 2. Instruments } \\
\text { dropped over the } \\
\text { patient }\end{array}$ & \\
\hline $\begin{array}{l}\text { Assistant provided } \\
\text { adequate saliva } \\
\text { evacuation }\end{array}$ & $\begin{array}{l}\text { 1. No pooling of } \\
\text { saliva in back of } \\
\text { throat }\end{array}$ & $\begin{array}{l}\text { 1. Saliva pools in } \\
\text { throat } \\
\text { 2. Saliva evacua- } \\
\text { tion unsatisfactory } \\
\text { for procedure per- } \\
\text { formed }\end{array}$ & \\
\hline $\begin{array}{l}\text { Assistant provid- } \\
\text { ed adequate tissue } \\
\text { retraction }\end{array}$ & $\begin{array}{l}\text { 1. Tongue and lips } \\
\text { were kept out of the } \\
\text { field of vision }\end{array}$ & $\begin{array}{l}\text { 1. Inadequate con- } \\
\text { trol of the oral tis- } \\
\text { sue in the field of } \\
\text { vision }\end{array}$ & \\
\hline $\begin{array}{l}\text { Assistant main- } \\
\text { tained proper pos- } \\
\text { ture throughout } \\
\text { procedure }\end{array}$ & $\begin{array}{l}\text { 1. Stool positioned } \\
\text { 4-6 inches higher } \\
\text { than the dentist } \\
\text { 2. Stool as close to } \\
\text { the dental chair as } \\
\text { possible }\end{array}$ & $\begin{array}{l}\text { 1. Assistants chair } \\
\text { out of position or } \\
\text { too far from the } \\
\text { dental chair }\end{array}$ & \\
\hline $\begin{array}{l}\text { Assistant cleaned } \\
\text { the "operatory" } \\
\text { after procedure }\end{array}$ & $\begin{array}{l}\text { 1. Instruments, den- } \\
\text { tal materials and } \\
\text { work area cleaned } \\
\text { and disinfected }\end{array}$ & $\begin{array}{l}\text { 1. Inadequate } \\
\text { cleanup. }\end{array}$ & \\
\hline
\end{tabular}




\section{Proximal- occlusal preparation for Resin Composite}

\begin{tabular}{|c|c|c|c|c|c|}
\hline Criterion & Clinically Acceptable & Not Clinically Acceptable & Comments & Student Self & Faculty Eval- \\
\hline Isolation & Rubber dam is properly placed. & Rubber dam is not functional. & & & \\
\hline External Form & $\begin{array}{l}\text { 2. All carious grooves / defects } \\
\text { are included } \\
\text { 3. The smallest condenser fits in } \\
\text { all aspects of the preparation } \\
\text { 4. Proximal and gingival contacts } \\
\text { are visibly and minimally open }\end{array}$ & 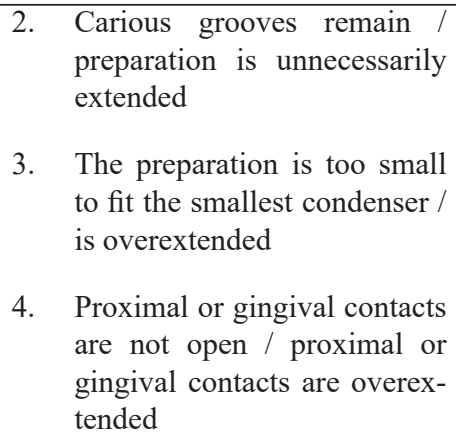 & $\begin{array}{l}\text { manikin isthmus } \\
\text { width }>1.6 \mathrm{~mm} \text { is } \\
\text { not acceptable } \\
\text { manikin proximal } \\
\text { wall extension } \\
>1.0 \mathrm{~mm} \text { is not } \\
\text { acceptable }\end{array}$ & & \\
\hline Internal Form & $\begin{array}{l}\text { 5. The pulpal floor is sufficiently } \\
\text { deep to remove carious tooth } \\
\text { structure } \\
\text { 6. The axial wall follows the outer } \\
\text { contour of the tooth and I is in } \\
\text { dentin } \\
\text { 7. Marginal ridge is supported by } \\
\text { dentin } \\
\text { 8. Buccal and lingual walls are } \\
\text { slightly convergent or parallel } \\
\text { (occlusal and box) } \\
\text { 9. Mesial / distal walls are slightly } \\
\text { divergent } \\
\text { 10. Axial alignment of the prepara- } \\
\text { tion is proper } \\
\text { 11. The axiopulpal line angle is } \\
\text { rounded or beveled }\end{array}$ & $\begin{array}{l}\text { 5. Carious tooth structure re- } \\
\text { mains or the pulpal floor is } \\
\text { excessively deep } \\
\text { 6. The axial wall is too deep } \\
\text { 7. Marginal is unsupported or } \\
\text { undermined } \\
\text { 8. Buccal and lingual walls are } \\
\text { divergent (occlusal or box) } \\
\text { 9. Mesial / distal walls are con- } \\
\text { vergent } \\
\text { 10. Axial alignment does not fol- } \\
\text { low the long axis of the crown } \\
\text { of the tooth } \\
\text { 11. The axiopulpal line angle is } \\
\text { sharp }\end{array}$ & $\begin{array}{l}\text { Manikin pulpal } \\
\text { floor }>3.0 \mathrm{~mm} \text { is } \\
\text { not acceptable } \\
\text { manikin ideal axi- } \\
\text { al wall depth (M - } \\
\mathrm{D}) \text { is ideally } 1.25 \\
\mathrm{~mm} \\
\text { manikin axial } \\
\text { wall depth (M - } \\
\mathrm{D})<1.0 \mathrm{~mm} \text { or }> \\
1.6 \text { mm is not ac- } \\
\text { ceptable } \\
\text { manikin marginal } \\
\text { ridge }<1.0 \mathrm{~mm} \text { is } \\
\text { not acceptable }\end{array}$ & & \\
\hline
\end{tabular}

\section{CDMI}

Blood Pressure, Pulse and Respiration Measurement - Evaluation Form

(Student mark finding with an X)

(Instructors circle student's findings to verify or comment if they disagree)

Student Name: Date:

Faculty Name:

Check One Column Below For Each Applicable Criteria 
Citation: Drahos GL (2017) Preclinical Patient Case Scenario as an Aid to Clinic Preparation: “A Day in the Clinic". J Dent Sci Res Ther 2017 : 1-16.

\begin{tabular}{|c|c|c|}
\hline Criteria & Satisfactory & Unsatisfactory \\
\hline \multicolumn{3}{|l|}{$\begin{array}{l}\text { 1. Patient has no medical contradictions to taking blood pressure with } \\
\text { cuff and stethoscope }\end{array}$} \\
\hline \multicolumn{3}{|l|}{$\begin{array}{l}\text { 2. Appropriate Patient Position- feet on floor, patient seated upright, arm } \\
\text { at level of heart }\end{array}$} \\
\hline \multicolumn{3}{|l|}{$\begin{array}{l}\text { 3. Arm supported appropriately (arm stable and supported by operator or } \\
\text { tabletop at level of heart) }\end{array}$} \\
\hline \multicolumn{3}{|l|}{$\begin{array}{l}\text { 4. Pressure cuff appropriately position (Arrow over brachial artery or as } \\
\text { directed by manufacturer) }\end{array}$} \\
\hline \multicolumn{3}{|l|}{$\begin{array}{l}\text { 5. Stethoscope properly position (in ears and positioned over the brachial } \\
\text { artery)) }\end{array}$} \\
\hline \multicolumn{3}{|l|}{$\begin{array}{l}\text { 6. Accuracy of blood pressure reading (faculty to verify BP within } 5 \text { points } \\
\text { of students reading) }\end{array}$} \\
\hline \multicolumn{3}{|l|}{ Blood Pressure Student } \\
\hline \multicolumn{3}{|l|}{ Blood Pressure Faculty $\overline{ }$} \\
\hline \multicolumn{3}{|l|}{$\begin{array}{l}\text { 7. Accurately recording of pulse (obtained over radial artery with finger } \\
\text { tips) Pulse }\end{array}$} \\
\hline \multirow{2}{*}{\multicolumn{3}{|c|}{$\begin{array}{l}\text { 8. Accurately recoding of Respirations } \\
\text { Respiration Rate }\end{array}$}} \\
\hline & & \\
\hline \multirow{2}{*}{$\begin{array}{l}\text { Faculty Evaluation } \\
\text { Scoring-Pass=No Unsatis., Fail=1 or more Unsatis. }\end{array}$} & & \\
\hline & & \\
\hline \multirow{2}{*}{$\begin{array}{l}\text { Self-Evaluation } \\
\text { Scoring-Pass=1 or fewer items on opposite side of } S / U \text { line when compared } \\
\text { to Faculty Evaluation. }\end{array}$} & & \\
\hline & & \\
\hline $\begin{array}{l}\text { Comments are required for any grade in the Unsatisfactory column } \\
\text { and are encouraged for all others as well. Comments may also be } \\
\text { written on the back of this form. }\end{array}$ & & \\
\hline
\end{tabular}

- Proper Case Presentation

- Demonstrate correct method to acquire patient BP - blood pressure is a vital sign that needs to be measured each appointment. Students A and B will demonstrate on each other the correct method of acquiring a blood pressure and pulse using the cuff and stethoscope technique.

- \#18 MO restoration criteria form- amalgam or composite - Student A doing this restoration must defend their decision to use amalgam or composite - the dental history clearly states that the patient wants "I want my teeth fixed. I want the strongest fillings you can place. Please make them esthetics, but metal fillings are OK also". Either restorative material can be defended to qualify for this restoration as well as the patients desires, but the student must present EBD material that defends their decision. The patient (faculty) may be questioned by the student at this point to help with the restorative material selection. The faculty may also question the student as to any statement they may make it their decision. The student must the select the criteria sheet that will be used in the cavity preparation and restoration placement. The attached radiograph illustrates caries that extends into the dentin in a fairly ideal pattern so that in either case the student should determine that an ideal cavity preparation can be made. The student will self-assess their performance using the criteria forms and the faculty will assess the final product using clinically acceptable grading protocol.

- Full Cast Crown prep for \#30 - Student B doing this aspect of the session- must present with the correct criteria forms for the cast crown preparation and the provisional crown and must perform the procedures to clinical standards.

- Triple Tray Impression for \#30 crown- this must be performed by student B to clinical standards (only one attempt will be allowed. If the results are not acceptable, the student will be allowed to explain the deficiencies with steps that would be taken to correct the deficiency)

- Provisionalization of \#30 to clinical standards-this must be performed by student B to clinical standards (only one attempt will be allowed. If the results are not acceptable, the student will be allowed to explain the deficiencies with steps that would be taken to correct the deficiency) 
- Proper use of dental assistant- Student A and B will be graded as they assist each other. Organization of the work area and correct technique are essential.

- The students will Identify the tongue lesion as geographic tongue or benign migratory glossitis that requires no treatment

- Each student will enter the patient blood pressure for today (stated in the narrative) into EHR

- Daily treatment note will be entered into each student's patient record.

- Procure and attach radiograph of \#30 to EHR using radiography and the HER

\section{Appendix E: Checklist for Student A and B}

\begin{tabular}{|c|c|c|c|c|}
\hline \multicolumn{5}{|c|}{ Appendix E-Student A } \\
\hline \multirow[t]{2}{*}{$\sqrt{ }$} & \multicolumn{4}{|c|}{ Checklist for Day in the Clinic (all criteria forms must contain self assess. } \\
\hline & Date: & Faculty: & Satisfactory & Unsatisfactory \\
\hline \multicolumn{5}{|c|}{ Student A (18 MO) Name: } \\
\hline 1 & Proper Case Presentation & & & \\
\hline 2 & $\begin{array}{l}\text { Demonstrate correct meth- } \\
\text { od to acquire patient BP }\end{array}$ & & & \\
\hline 3 & $\begin{array}{l}\text { \#18 MO preparation cri- } \\
\text { teria form (amalgam or } \\
\text { composite- must defend } \\
\text { selection) }\end{array}$ & & & \\
\hline 4 & $\begin{array}{l}\text { \#18 MO restoration criteria } \\
\text { form (amalgam or compos- } \\
\text { ite- must defend selection) }\end{array}$ & & & \\
\hline 5 & $\begin{array}{c}\text { Correct Use of the Rubber } \\
\text { Dam }\end{array}$ & & & \\
\hline 6 & $\begin{array}{c}\text { Proper Use of Dental As- } \\
\text { sistant }\end{array}$ & & & \\
\hline 7 & $\begin{array}{l}\text { Identify tongue lesion as } \\
\text { geographic tongue or be- } \\
\text { nign migratory glossitis- } \\
\text { no tx }\end{array}$ & & & \\
\hline 8 & $\begin{array}{r}\text { Enter patient's BP into } \\
\text { EHR }\end{array}$ & & & \\
\hline 9 & Daily tx Note & & & \\
\hline 10 & $\begin{array}{l}\text { Procure and attach radio- } \\
\text { graph of } \# 30 \text { to EHR }\end{array}$ & & & \\
\hline 11 & Final Assessment & & & \\
\hline
\end{tabular}

\begin{tabular}{|c|c|c|c|c|}
\hline \multicolumn{5}{|c|}{ Appendix E-Student B } \\
\hline \multirow[t]{2}{*}{$\sqrt{ }$} & \multicolumn{4}{|c|}{ Checklist for Day in the Clinic (all criteria forms must contain self assess.) } \\
\hline & Date: & Faculty: & Satisfactory & Unsatisfactory \\
\hline \multicolumn{5}{|c|}{ Student B (\#30 crown prep, provisional and impression) Name: } \\
\hline 1 & Proper Case Presentation & & & \\
\hline 2 & $\begin{array}{l}\text { Demonstrate correct meth- } \\
\text { od to acquire patient BP }\end{array}$ & & & \\
\hline 3 & $\begin{array}{l}\text { Full Cast Crown prepara- } \\
\text { tion for tooth } \# 30 \text { (criteria } \\
\text { form- self assessment) }\end{array}$ & & & \\
\hline 4 & $\begin{array}{l}\text { Triple tray impression for } \\
\# 30 \text { crown (only one at- } \\
\text { tempt-explain deficiencies } \\
\text { if Unsatis) }\end{array}$ & & & \\
\hline 5 & $\begin{array}{l}\text { Provisionalization for } \# 30 \\
\text { (criteria form-self assess- } \\
\text { ment) }\end{array}$ & & & \\
\hline 6 & $\begin{array}{c}\text { Proper Use of Dental As- } \\
\text { sistant }\end{array}$ & & & \\
\hline 7 & $\begin{array}{c}\text { Identify tongue lesion as } \\
\text { geographic tongue or be- } \\
\text { nign migratory glossitis-no } \\
\text { tx }\end{array}$ & & & \\
\hline 8 & Enter patient's BP into EHR & & & \\
\hline 9 & Daily tx Note & & & \\
\hline 10 & $\begin{array}{l}\text { Procure and attach radio- } \\
\text { graph of } \# 30 \text { to EHR }\end{array}$ & & & \\
\hline 11 & Final Assessment & & & \\
\hline
\end{tabular}

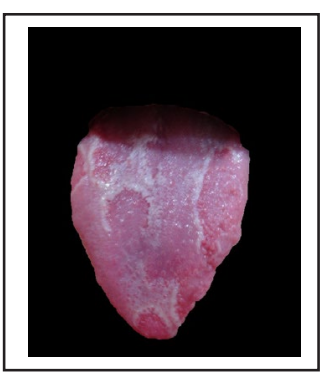

Image owned by Mary Anne Byrnes used with permission.

\section{Notes:}

All dental procedures required in this case are familiar to the students and have been performed as coursework during first two years. Student's work independently checking only final products with the faculty (completed amalgam or composite prep, completed restoration, crown prep, impression and provisional restoration). Students self-assess their work using criteria sheets that are procedure specific (Appendix D). These criteria forms were created throughout the first 2 years as part of dental curriculum. The forms were posted and 
the student was expected to print these forms in advance and complete their self-assessments independently. Each session was 3.5 hours in duration (the same as the length of our clinic session) and was worth $1 \%$ of the student's grade in the course for successful completion.

\section{Faculty duties during the session:}

During the session, the faculty is not to intervene, or steer the student to accomplish any particular component in a certain way.

\section{The faculty can do the following:}

1. Advise the student of the time constraints during the course of the session if they feel the students is lagging behind.

2. If the student has prepared the wrong tooth, or proceeded in any fashion without proper authority (preparation not checked before restoration placed) the faculty will allow the student to proceed to completion before being advised of their error that will result in an unsatisfactory grade.

3. Since this is meant to be a learning experience in addition to a test, the faculty s allowed to let the student "rethink" their decisions before proceeding.

4. The faculty will not monitor the student's self-assessment (criteria sheets) to verify if their self-assessment of their work is accurate. If there is a difference in opinion between the faculty supervisor and the student's self-assessment, discussion and evaluation of the criteria sheet will take place after the session.

5. The faculty must approve all EHR entries.

6. At the completion of the session, the faculty will promptly advise the students (individually) of success or failure on the scenario with reasons for this decision. The faculty will enter these comments on the grade sheet for each student and advise the course coordinator so the results can be posted immediately.

7. The faculty is not to give instruction to the students on procedures.

8. The faculty will answer all question that the student may have of the patient.

9. The faculty will ask any question (as the supervising faculty, or in the role as the patient) to determine preparedness or knowledge of the students.

\section{Appendix F: Daily Treatment Note}

\section{Daily Treatment Note Template and sample note}

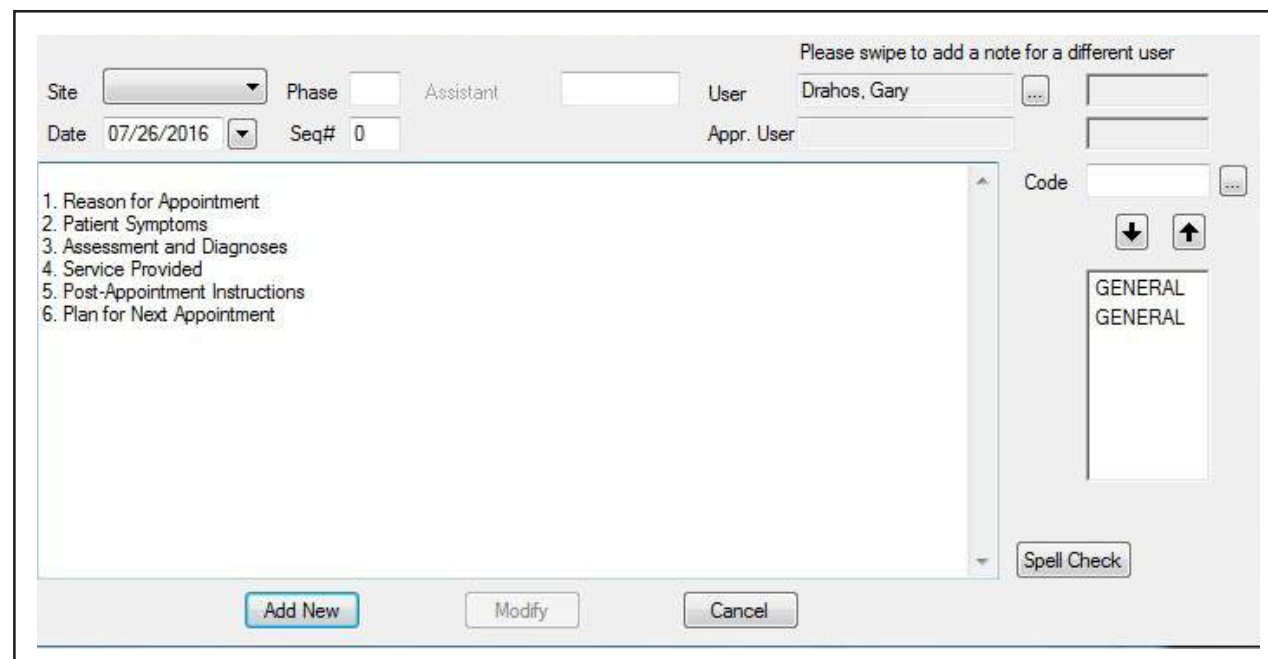

A. Template for daily treatment general. 


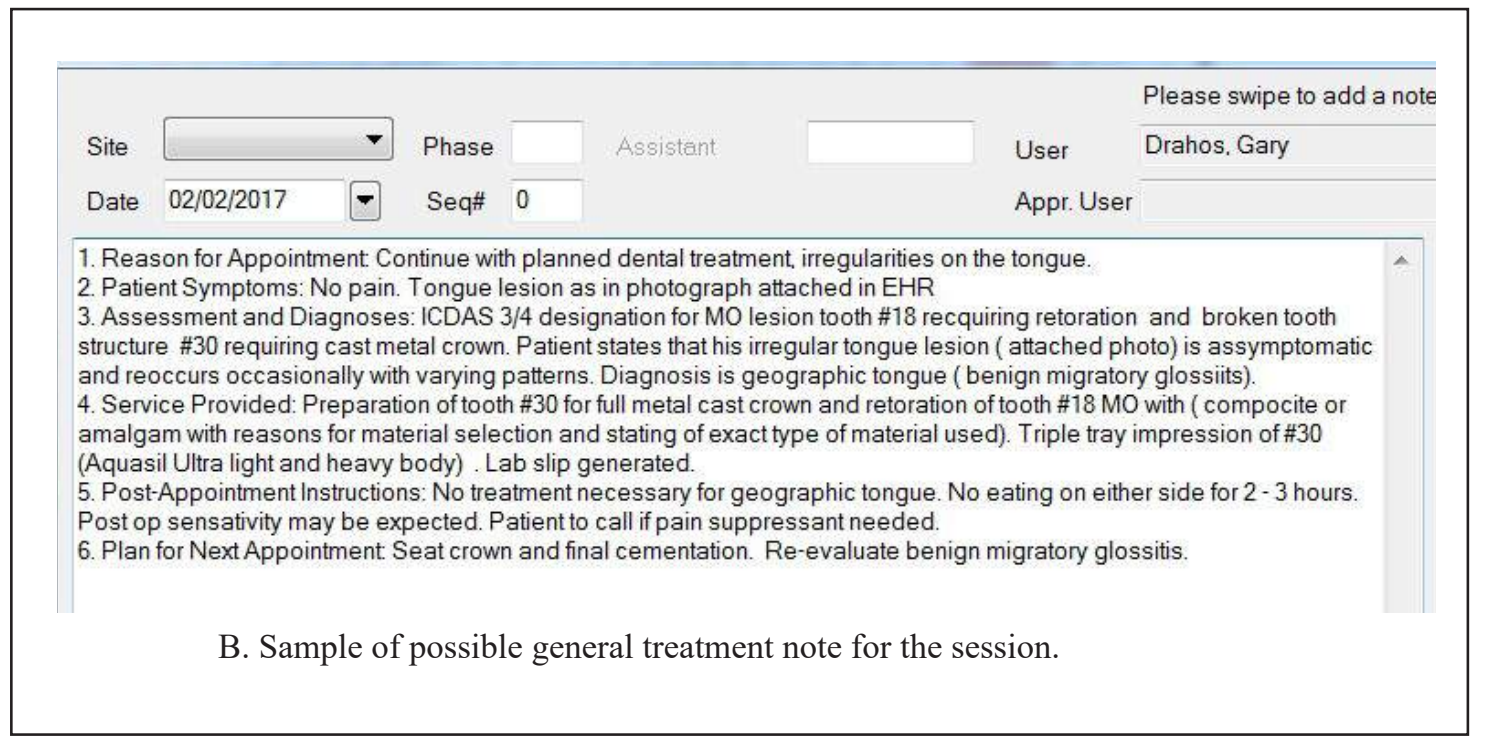

\section{Appendix G: Session material and instruments used, facility needs and time allotments}

\section{Dental Materials needed: (Photos attached below)}

- Composite, bonding adhesive, light cure source, polishing disc

- Amalgam, trituration equipment, amalgam placement dental equipment

- Impression materials, triple tray

- Manikin, high and low speed, suction and air supply (Appendix C)

- Cuff and stethoscope

- Restorative Cassette

- Rubber Dam Cassette

\section{Session Preparation:}

\subsection{Pre session (Students)}

- Calibration to sessions

- Simulated patient electronic health record data

- Review of restorative procedures to be performed and assemble appropriate criteria sheets for self-assessments and faculty reference

- Patient narrative scenario

- Practice session with assigned student partner

\subsection{Post session (Students)}

- Review criteria sheet evaluations with instructor

- $\quad$ Receive instructor feedback

- Written multiple choice exam

- Session evaluation 


\subsection{Pre session (Faculty)}

- $\quad$ Review criteria grading checklist

- Calibration presentation

\section{Facility Needs}

- Pre-clinical dental simulation facilities containing mannequin heads and dental instrumentation commonly use in dental education for simulated patient care training. Digital dental imaging equipment.

\section{Time allotment (Student)}

- Time for pre session calibration lecture - 1 hour lecture

- Time for independent preparation for session - 1-2 hours practice time

- Actual Session - 31/2 hours

\section{Faculty requirements}

- Faculty calibration - 1 hour

- Adequate faculty/student ratio for effective simulation training-recommend 1:8

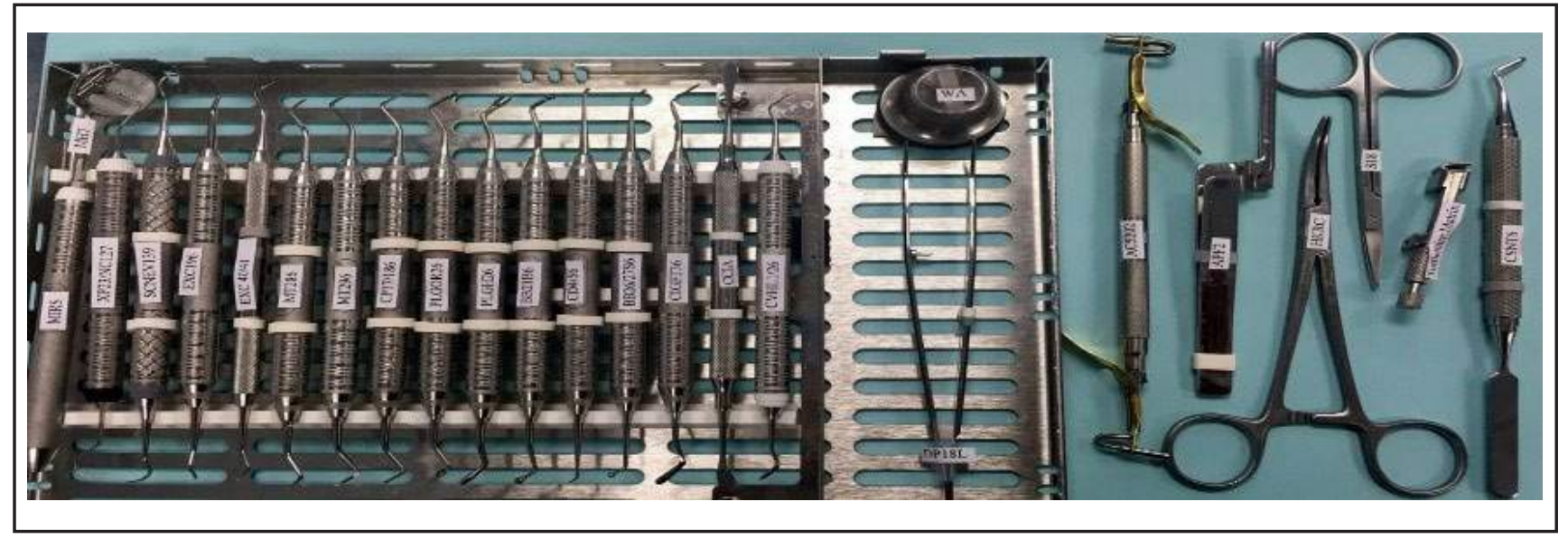

\section{Restorative Operative/Fixed Kit}

1. MIRS

2. $\mathrm{MH7}$

3. $\mathrm{XP} 23 / \mathrm{NC} 127$

4. $\quad$ EXC196

5. SCNEV139

6. $\quad$ EXC 40/41

7. MT286

8. MT296

9. CP17/186

10. PLGOR26

11. PLGH26\#6 Hollenback Plugger, Satin Steel

12. BB21B6

13. CD $4 / 56$
\#21 Acorn Burnisher

\# 5 FS CS Mouth Mirror, Single

\#7 Cone Socket Mirror Handle

Explorer/Perio Probe

\#19 DE Excavator, Stain Steel

\#3 Navi Scaler Posterior DE, EverEdge \#9

\#40/41 DE Excavator

\#28 DE Margin Trimmer, Satin Steel

\#29 DE Margin Trimmer, Stain Steel

\#17/18 Hatchet

\#2 Hollenback Plugger, Satin Steel

\#4/5 DE Cleiod-Discoid Carver, Satin Steel 


$\begin{array}{lll}\text { 14. } & \text { BB26/27S6 } & \text { \#18 Ball Burnisher Satin Steel } \\ \text { 15. } & \text { CIGFT36 } & \text { \#3 Goldstein Flexi- Thin Compos Inst } 6 \\ \text { 16. } & \text { CCIA } & \text { \#A Cosmetic Contouring Inst. } \\ \text { 17. } & \text { CVHL1/26 } & \text { \#1/2 Hollenback De Carver, Satin Steel } \\ \text { 18. } & \text { DP18L } & \text { \#18L Dressing Pliers (Non Locking) } \\ \text { 19. } & \text { WA } & \text { Amalgam Well } \\ \text { 20. } & \text { AC5202 } & \text { CF II Amalgam Carrier DE Regular/Large } \\ \text { 21. } & \text { APF2 } & \text { Articulating Paper Forceps } \\ \text { 22. } & \text { CSNT6 } & \text { \#6 Novatech DE Long \& Loading } \\ \text { 23. } & \text { S18 } & \text { \#18 Iris Scissors, Carved } \\ \text { 24. } & \text { HKRC } & \text { Kelly-Rankin Hemostat } 6.5 \text { in Curved Tofflemire Matrix }\end{array}$

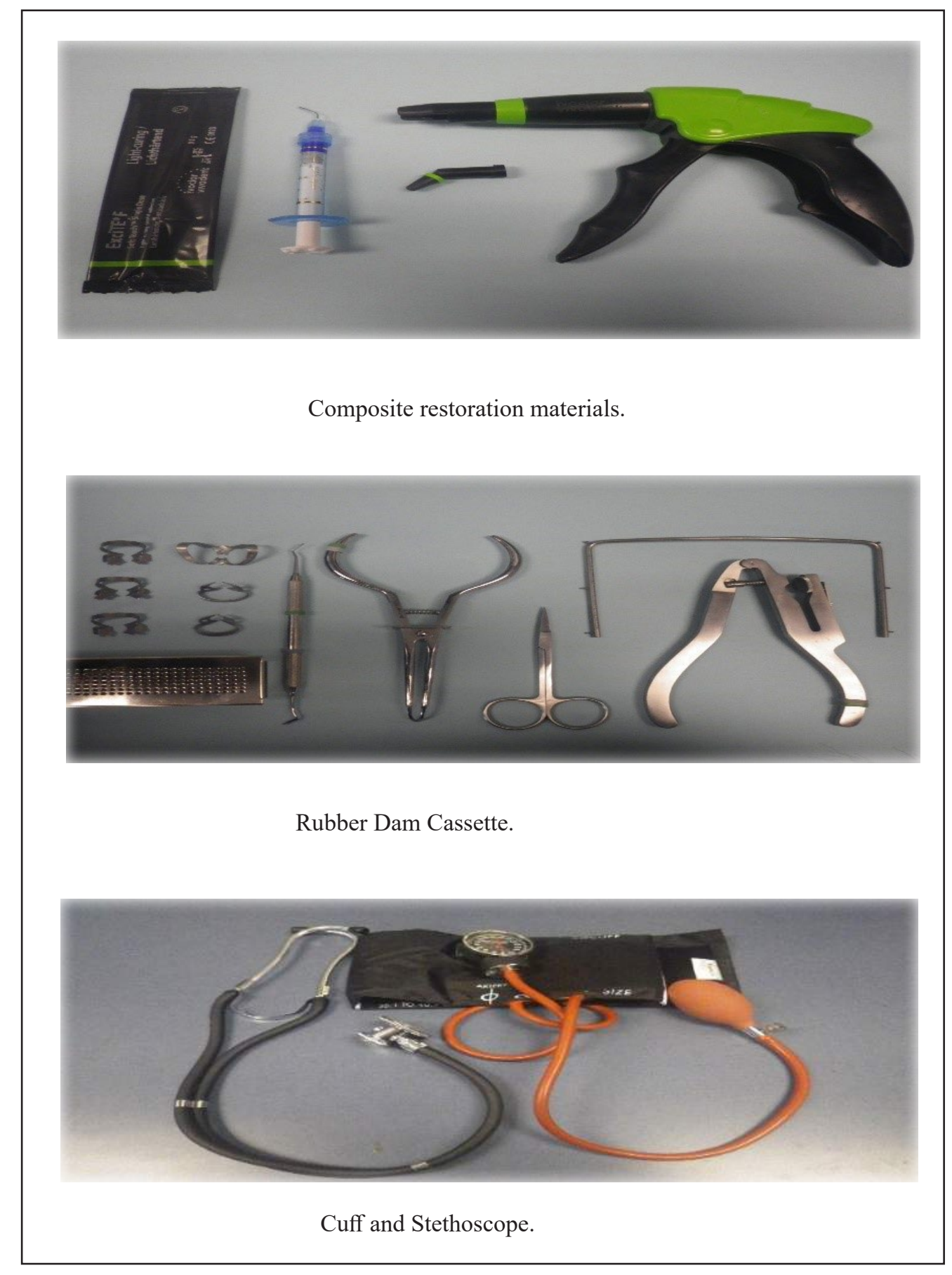

